\title{
La ciudad marroquí en Los nombres del aire de Alberto Ruy Sánchez y Aguafuertes españolas de Roberto Arlt
}

\author{
Abdellatif Limami \\ Dhar el Mehraz Fez, Marruecos
}

Muy escasas son las investigaciones realizadas en el campo de la literatura sobre un tema de gran interés: la presencia árabe en la literatura latinoamericana; una insuficiencia que ciertos críticos califican con razón de "tesis del olvido en la historia"1.

Muy recientemente, hispanistas marroquíes especialistas en literatura y civilización del nuevo mundo intentan dar a conocer la manera con que este trasfondo sociocultural árabe-islámico queda utilizado en la narrativa latinoamericana. Así, se ponen en tela de juicio obras de importantes creadores en que este tema queda utilizado a través de prejuicios, con cierta ambigüedad, a partir de un conocimiento falso o superficial; o, por el contrario, mediante un acercamiento objetivo e imparcial.

En efecto, poco importa si la visión que nos dan concuerda con la realidad sociocultural o no. Es tarea de los investigadores nativos la de comunicar y completar esta visión ciel mundo. Lo más importante es que se establezca esa comunicación y nos sirva de puente que facilite el diálogo.

1. Ver Sergio Macías, «Presencia árabe en la literatura latinoamericana. Tesis del olvido dentro de la historia», La mañana del Sahara y del Magreb (Casablanca, Marruecos, 17 a 21 de julio de 1990). 
Conforme con lo señalado, me propongo acercarles a la recreación de dos espacios urbanos marroquíes: Tánger (el norte de Marruecos) en los trabajos periodísticos del argentino Roberto Arlt en sus Aguafuertes españolas ${ }^{2}$ y Mogador (la actual Essaouira) en Los nombres del aire del mexicano Alberto Ruy Sánchez ${ }^{3}$.

$$
* * *
$$

Roberto Arlt (Argentina, 1900-1942), forma parte de los autores latinoamericanos que establecieron un contacto con la sociedad marroquí (con el norte de Marruecos, en concreto). Como creador, se sirvió de este contacto para interpretar, a su manera, una atmósfera. Así en $1938^{4}$, publicó África, en la que se expresa un dramaturgo fascinado por lo pintoresco, la riqueza de los colores y lo sensacional. En el mismo sentido publicó El criador de gorilas (1941): serie de cuentos en la que reaparecen ciertos motivos y temas de la experiencia africana ${ }^{5}$.

Toda esta temática, desarrollada en la obra de ficción, puede ser considerada como un intento, por parte del autor, de reelaboración de un conjunto de temas ya desarrollados en Aguafuertes españolas, ensayos periodísticos publicados en 1936.

Como el título lo indica, se trata de artículos periodísticos o de crónicas donde Arlt intenta grabar ciertos aspectos de la vida cotidia$\mathrm{na}^{6}$. Y siempre con respecto al título, se imponen dos aclaraciones:

1. después del éxito de Aguafuertes porteñas $(1933)^{7}$, el autor fue invitado a efectuar un viaje por España como corresponsal del periódico argentino El mundo; viaje que tuvo ocasión en 1935; y

2. Roberto Arlt, Aguafuertes españolas, en Obras completas (Buenos Aires: Carlos Lohlé, 1981) II, 259-371.

3. Alberto Ruy Sánchez, Los nombres del aire (México: Joaquín Mortiz, 1988).

4. Roberto Arlt, África (Drama en cinco actos y un exordio al uso oriental), en Obras completas, II, 557-619.

5. $\quad$ Roberto Arlt, El criador de gorilas, en Obras completas, tomo I, 839-943.

6. Aguafuerte: grabado que se obtiene dibujando directamente con una punta acerada o buril sobre una plancha de acero, cobre o zinc, previamente cubierta de una capa de barniz, vertiendo ácido nítrico sobre la plancha una vez dibujada. El ácido, al corroer las partes dejadas al descubierto por el buril, de ja la plancha labrada en hueco.

7. Roberto Arlt, Aguafuertes porteñas, en Obras completas, ed. cit. 
2. los textos sobre Marruecos (Tánger y Tetuán) ocupan un lugar muy modesto en esta obra, centrada más en España que en Marruecos (de las 102 páginas de la obra, solo 24 se dedican a Marruecos).

Los artículos que tocan el mundo marroquí son introducidos bajo el título de «Marruecos», y distribuidos en diez subdivisiones: «Tánger», «El narrador de cuentos», «El trabajo de los niños y las mujeres», «La danza voluptuosa», «El mercader oriental y las mil y una noches», «Casamiento morisco», «Noviazgo moro en Marruecos en el año 1935», «La vida campesina en la ficción y en la realidad», «Tetuán, ciudad de doble personalidad» y «Salida de Tetuán».

Del total de ocho artículos consagrados a Tánger, el primero es el más descriptivo; sirve para introducir un espacio. Y en cuanto a los demás artículos, sirven respectivamente para poner de relieve un conjunto de costumbres y tradiciones (el narrador de cuentos, una danza, un matrimonio) o para describir y tomar postura frente a problemas sociales (el trabajo de los niños y las mujeres en Marruecos de entonces, la vida de los campesinos).

Las fuentes inspiradoras del autor durante la realización del presente trabajo son diversas, y prácticamente todas externas, a saber:

1. Las colonias extranjeras instaladas en el Tánger internacional de aquel entonces ${ }^{8}$ :

El matrimonio significa para la musulmana cambiar de prisión doméstica. Algunas sufren horriblemente en la proximidad de su matrimonio con un desconocido. Una señora europea que conversa algo en árabe, me contaba que aquí en Tánger, vive la hija de un ex bajá (gobernador) de Fez; hace cinco años que se casó;

8. En 1921 se creó la Zona Internacional del Tánger, que gozó a partir de 1923 de un régimen especial (Estatuto firmado por España, Francia e Inglaterra, a las que se unió Italia en 1928). 
su esposo la condujo en automóvil desde Fez a Tánger, llegaron de noche a ésta, y ella confiesa que no ha salido a la calle aún, y que por lo tanto ignora la estructura de la ciudad (329).

Una europea poco pudibunda me ha afirmado que "tienen [las mujeres] una facilidad extraordinaria para asimilar los vicios europeos" (330).

Un comerciante, hace muchos años radicado en Tánger, me asegura que las musulmanas viven rabiosas de su estado al cual no tienen miras de poner remedio en la actualidad (330).

2. La gente del pueblo (una red de información mucho menos desarrollada que la primera, debido seguramente a un problema de comunicación: la lengua árabe):

El trabajo de estas criaturas (y los datos los obtengo del dueño de una chilabería) comienza a las siete de la mañana y se interrumpe a las doce. A la una y media de la tarde vuelven los niños a entrar al taller, y salen a las ocho o nueve de la noche (319).

3. La observación y el contacto directo con ese universo:

Descaradamente me instalo — subraya Roberto Arlt- en el cajón de un mercader, entre un círculo de moras, y desde allí, semejante a un rey mago, me dedico a observar el trajín del mercado (311).

Es la clásica imagen del periodista en busca de más impresiones por las estrechas callejuelas de Tánger (ver 319).

4. El conocimiento a priori de la sociedad marroquí (o del mundo árabe de manera general). Es una fuente casi inexistente y sin importancia en este trabajo de Arlt: 
- $\quad$ referencia al personaje mítico y legendario de Jeha;

- referencia a Las mil y una noches; y

- referencia especial al cuento «Alí Baba y los cuarenta ladrones».

El punto de vista que determina esos artículos va en el sentido de esta experiencia vivida desde fuera: utilización del yo testigo o privilegiado, o de todo artificio lingüístico que va en el mismo sentido.

1. Utilización de la segunda persona del singular (usted) para referirse al turista no advertido, pero que recae o incluye también la personalidad del autor:

Levanta usted la mirada de su diario, el mejor procedimiento para sacarse de encima a los vendedores de baratijas, y allí, ubicado uno tras de una columna, otro bajo un arco [...] Se marcha usted a almorzar. Vuelve al café. Pues allí están los guías. Esperándole [...] — Fuera — grita usted rabioso [...] y se marchan. Usted se cree por fin solo; a las tres cuadras, nuevamente los fulanos que brotan de un embrollado laberinto de callejuelas [...] Se mete usted al café. "Se han marchado", piensa usted respirando, pero no, queda uno, inmóvil junto a una columna (310).

2. Utilización del pronombre indefinido uno, para referirse a su propia persona. Este recurso predomina al principio de estos artículos como preámbulo al yo testigo:

Frente a la tenacidad y a la cortesía del guía "uno no sabe si echarse a reír o emprenderla a puntapiés con un hombre tan perfectamente educado" (310). 
Frente a la unanimidad de colores violetas, té, café, que ofrece el zoko "uno llora por dentro de no tener ojos en las sienes, en la nuca" (326).

Y, en fin, frente al espectáculo que ofrece un matrimonio morisco (novia encerrada en una especie de jaula), "uno no sabe por qué, siente ganas de llorar" (326).

3. Sin embargo, el punto de vista predominante en esos artículos es el yo, testigo privilegiado y actor a veces de las situaciones descritas. Roberto Arlt se instala en los diferentes espacios de la ciudad para "observar el trajín del mercado" (311), "flirtear con las moritas por excepción bonitas", y saludarlas "al modo oriental" (312), acercarse a las jóvenes campesinas que lo miran "extáticas, arrobadas" (312); en resumidas cuentas, para "gozar" y "paladear" "el espesor de esta atmósfera tosca y brutal" (312).

En un tono patético, lleno de emoción y compasión, este yo reviste, finalmente, la forma de un testigo ocular de un conjunto de realidades extraídas de la vida cotidiana en Tánger, y que provocan en el periodista una terrible indignación: el triste espectáculo de niños sometidos a un régimen espantoso de trabajo, mujeres cargadas de enormes fardos de leña seguidas por sus maridos, montados en un burro (ver 320).

Este punto de vista va, finalmente, en el sentido de estas Aguafuertes españolas que toman en los artículos periodísticos de Arlt el valor de expresiones, notas y esquicios en que queda grabada (con un humor a veces sarcástico) la vida cotidiana de los hombres.

Sin embargo, este cuadro de costumbres - pese al deseo de objetividad y realismo del periodista - se percibe desde fuera, y sufre de una carencia de informaciones relacionadas con el "otro" y sobre todo con la cultura y civilización del "otro". La corta estancia de Arlt cn Marruecos, su desconocimiento del mundo y la cultura arábigo- 
islámicos, así como la dificultad de comunicación debida al idioma, son factores que originaron esta visión externa. Y Roberto Arlt lo admite; en un artículo consagrado a lo que denomina "la vida vulgar de los campesinos" subraya lo siguiente:

Yo ahora les voy a hablar de una campesina marroquí [...] Hablaré con la más enorme de las ignorancias y con el más extraordinario de los desconocimientos [...] tal cual la he visto desde la ventanilla de un autobús (331).

Lo anterior concuerda con el lector potencial para el cual Arlt escribía estos artículos. El receptor no era más que el lector argentino no advertido y sediento de todo lo que es pintoresco, exótico y lleno de colores. "A través de estas páginas sobre Tánger", dice Raúl Castagnino, se invitaba al lector a "penetrar en un ámbito de exotismo ni siquiera presentido" y a "internarse en un fabuloso mundo miliunanochesco"'.

El tiempo, de mucha importancia en estos artículos, nos permite situar con facilidad la estancia de Roberto Arlt en Marruecos (Tánger) en 1935: históricamente en un momento cuando la ciudad era considerada como zona internacional codiciada por las grandes potencias de aquel entonces. Es el Tánger internacional donde conviven (según Arlt) los vicios más extraordinarios y donde todo está permitido:

pasa un viejo gordo, barba en punta, apoyado dulcemente en un mancebo fino como una señorita, con el fez coquetonamente inclinado, la mirada de gacela; pasa una norteamericana rubia, con pantalón gris y fumando un cigarro de papel achocolatado (314).

Es el Tánger "de los caminos asfaltados [...] donde se pasan las películas de Joan Crawford y se dictan cursos por correspondencia, y funcionan estaciones de radio" (331). Es el Tánger nostálgico, donde

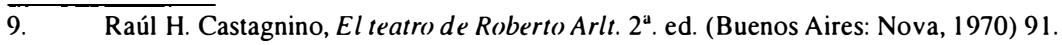


las europeas "vienen a hacer compras, seguidas de moritos enfáticos, descalzos, con pantalones bombacha recamados de oro", y donde pasean "inglesas de traje sastre" y "cocotas francesas tremendamente escotadas" (312).

Los microespacios que integran el Tánger descrito por Arlt revelan la naturaleza de estos artículos, así como la voluntad del autor de conducir al lector no iniciado a los espacios más turísticos y típicos. Respectivamente, pasamos del puerto a la calle, al café, al gran y pequeño zoológicos, y a las afueras de Tánger, en dirección a Tetuán. Se trata del clásico recorrido del turista que visita el norte de Marruecos. El aspecto particular de esa descripción consiste en que se hace mediante el elemento humano que tiene la costumbre de frecuentar esos espacios: los mozos del puerto, los guías (calles y cafés), los campesinos (el Zoco). Para Arlt, al llegar al puerto el martilogio empieza:

Una cáfila de moros descalzos, negros, rapados, ancianos, niños con collares de roña en torno del cogote, se precipitan sobre las maletas con tal furor, que el viajero se ve obligado a solicitar la ayuda de la policía indígena (309).

En la calle, como en el café, sigue la misma persecución, orquestada esta vez por los vendedores ambulantes y los guías:

En cuanto el desdichado pone un pie en la calle, una brigada de guías moros que aguarda su salida, se precipitan a él, of reciéndole sus servicios, exhibiendo sus chapas de cobre (309).

Y refiriéndose a los vendedores ambulantes, dice:

Toda esta canalla, persistente, pegajosa, hediendo a manteca rancia, forma un círculo implacable, en torno a la mesa del turista (310). 
En cuanto a la visión que el escritor nos da del Zoco, es de las más satíricas. En su inactividad en el Zoco, los campesinos son calificados de "hombres siniestros como Boris Karloff en su caracterización de la Momia, tiesos, espectrales, picados de viruelas..." (314); y las campesinas son presentadas como "pequeños animalitos" (312), "por excepción bonitas" (312), y "prodigiosamente envejecidas" (314). Son raras criaturas, sin cultura, y que viven como verdaderas bestias; son seres cuya falta de cultura "las priva de elementos de lenguaje para expresar los matices que diferencian los estados de espíritu" (330), y cuya pobreza de sintaxis es, para Arlt, original "en seres humanos casi primitivos cuya conversación sólo se refiere a partes del vestido o de la alimentación" (330). Hablar con ellas equivale a "tratar de metafísica con una vaca, dotada, por un milagro, del don de la palabra". Estos son términos que no necesitan comentario.

En cuanto al mercader, está presentado en un espacio muy reducido; una especie de gruta de un metro y medio de ancho, por dos metros de altura, y otros tantos de profundidad, donde está condenado a engordar y a echar caderas inmensas (ver323). Su imaginación — sostiene Arlt-es tan estrecha como su tienda; lo que le da al escritor la ocasión de criticar la imaginación árabe caracterizada por pobreza e inactividad: frente al cuentista o novelista occidental que habría inventado un disparatado aparato para volar, se impone en el mundo árabe la alfombra mágica que implica menos esfuerzos; y frente al cuentista griego que habría librado el combate más fuerte para entrar en una caverna, existe en el mundo árabe la fórmula "Sésamo, ábrete", que implica también menos esfuerzos (ver 323-324).

Pero, frente a tal visión, subsiste otra que nos recuerda en más de un aspecto el tema del "buen salvaje". En el círculo formado por los atentos espectadores de las narraciones del cuentista árabe, y pese a la suciedad y los malos olores, uno respira: "Es como si se encontrara en un sanatorio de bestialidad profunda que le curara de esa larga y terrible enfermedad que se llama civilización" (316), lo cual corresponde con el cinismo que predomina en la obra de Arlt, sobre todo en Los siete locos y Los lanzallamas, donde reúne a siete personajes 
frustrados que intentan liberar al hombre de la Babilonia de los ticmpos modernos: la ciudad.

$$
* * *
$$

Los nombres del aire, de Alberto Ruy Sánchez, publicado en México en 1987, es un relato casi inusitado en la literatura de esa nación. Su acción —si podemos hablar de tal componente del género novelesco en este relato- se desarrolla en la ciudad marroquí de Mogador (la actual Essaouira), fundada por el rey Sidi Mohamed Ben Abdellah, en 1760. Más que de acción, la crítica habla de un inventario poético de las señas del deseo y de un descubrimiento de los placeres minuciosos del sexo; aspecto que recuerda al lector árabe la obra de Ibn Hazm al Andalusí El collar de la paloma ${ }^{10}$, que se cita en este relato.

Esto no constituye la única indicación que nos permite situar el relato en un espacio árabe-musulmán, o incluso marroquí. Otros detalles, unos más significativos que otros, le permiten al lector determinar el espacio donde transcurren los acontecimientos: alusión a elementos religiosos: "minarete", "Corán", "Meca" (66), "Alá" (107); referencia a afeites femeninos que utilizan sobre todo las mujeres árabes: "rasul" (tierra que se utiliza para lavar el pelo), "Kojol" (afeite que sirve tanto para proteger los párpados como para afeite); referencia a alimentos y objetos típicos de este mundo: "higos", "almendras", "dátiles" y "cojines"; referencia a un título de autoridades árabes: "caid"; alusión a microespacios muy característicos del mundo árabe-musulmán: "zoko" (25 y 33), "desierto" (34), "oasis" (34), "horno público" (50); detalles relativos a aspectos arquitectónicos típicos: "blancura de los muros" (74), "pared encalada" (49); referencia explícita a la ciudad marroquí "Fez" (60). En fin, mención de una herencia cultural arábigo-andaluza: la poesía arábigo-andaluza a través de la figura de Ibn Zaydun el Cordobés (1068-1091), autor de Qasida en num, uno de los más admirables poemas de amor arábigoandaluces (ver 77); la tradición del "Adab" (tratado a la vez narración

10. Ibn Hazm de Córdoba, El collar de la paloma. Trad. E. García Gómez (Madrid: Alianza). 
y poema, generalmente vivido en gran parte por el autor); "tradición muy arraigada en la literatura arábigo-andaluza", afirma el narrador (31); referencia a Ibn El Arabi, maestro espiritual por excelencia que ha ejercido durante varios siglos una gran influencia sobre el misticismo islámico, y que Alberto Ruy Sánchez cita para introducir uno de los capítulos de este relato (ver 71); referencia, en fin, y sobre todo, a Ibn Hazm al Andalusí, cuya obra Tawq al hamana (El collarde lapaloma) parece haber inspirado al autor de esta obra de ficción (ver 28 y 29).

Mediante Fatma, figura principal del relato, Ruy Sánchez describe cuerpos que se desean y personajes que se inician; y se construyen mundos imaginarios a partir de los propios deseos que experimentan en su cuerpo. Todo a través de una prosa poética y de infinitas metáforas visuales.

La cubierta del relato es en sí una buena introducción a este mundo novelesco determinado por una gran sensibilidad: recrea un fragmento de la «Odalisca», obra del pintor catalán Mariano Fortuny en 1861, y que forma parte de una serie de obras inspiradas en los viajes efectuados por el artista a Marruecos. La Odalisca es una bellísima mujer, que ostenta sus encantadoras formas, tendida en un diván ${ }^{11}$.

En las primeras páginas de Fortuny, Gimferrer describe el cuadro, que Ruy Sánchez reproduce en la portada de su obra, así:

La cabellera larga y negra de la Odalisca se esparce en el aire empalagoso y quieto. El cuerpo desnudo yace en una sábana blanca que cubre y sofoca un lienzo de un rojo exuberante y vívido [...] La Odalisca of rece el cuerpo, como of rece, abierta, la palma de la mano. Un árabe con turbante está sentado a sus pies ${ }^{12}$.

En el prólogo a la obra de Gimferrer, y en un intento por transmitir al lector sus propias impresiones de lectura, Octavio Paz se refiere a "una suerte de álbum visual hecho de palomas", "de un libro

11. Pere Gimferrer, Fortuny. Trad. B. Losada (Barcelona: Círculo de Lectores, 1987).

12. Gimferrer, 19. 
no para ser pensado sino visto pero a través de la lectura", y de escenas que desfilan ante los ojos del lector sin que tengan "la continuidad de un argumento lineal", sino que son más bien "los fragmentos dispersos de una historia"13.

La lectura de Los nombres del aire se inscribe en esos mismos parámetros:

- $\quad$ un tiempo despedazado y formado por trozos infinitos y vivos, y suscrito además en una de las estaciones más reveladoras y sugerentes: el otoño, que suele consagrarse a Dionisos, el dios símbolo, por antonomasia, del deseo amoroso;

- un espacio plural y discontinuo, pero que, a modo de un rompecabezas, forma una y única imagen;

- $\quad y$, por fin, una sucesión de imágenes visuales que invitan al lector (del mismo modo que la Odalisca) a seguir una serie de viajes iniciáticos.

El Mogador que nos of rece Ruy Sánchez es esencialmente un espacio cerrado y poetizado al máximo. Mogador aparece desde el principio como una isla encerrada por una blanca muralla. Los marinos la asimilan a una luna que los llama desde el agua, y añoran verla transformada en "un refle jo desnudo bajo el agua" (64). Constituye para ellos una especie de "ciudad desnuda como una amante esperando en un puerto" (45). En cuanto a sus murallas, son presentadas por el narrador como labios que "ejemplifican y modulan su canto" (45). Es, al fin y al cabo, y como lo afirma el narrador en las primeras páginas del relato, imagen del mundo, "un mapa de la vida tanto externa como espiritual de los hombres" (16).

Más allá de las referencias al deseo sexual que aparecen de manera explícita en estas citas ("ciudad desnuda", "ciudad amante", "murallas labios", "reflejo desnudo"), aparecen símbolos que hacen de la ciudad un espacio esencialmente cerrado y reductor, según la

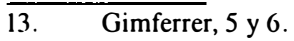


psicología de los personajes: "muralla" (que además de ser tradicionalmente un recinto protector, es igualmente cárcel, pasividad, sofocación y ahogo); "isla" (símbolo de aislamiento del mundo, pero al mismo tiempo lugar sagrado de elección, frente a la agitación y la ignorancia del mundo profano).

De acuerdo con esta percepción reductora del espacio (que no facilita el contacto con el mundo exterior), la alcoba de Fatma es otro lugar-claustro, cuya conexión con el mundo exterior queda determinada por una ventana protegida con una celosía de madera:

La gran celosía de madera enmarcaba la ventana de Fatma, recortaba los rayos del sol en formas geométricas que semejaban estrellas. Un pequeño universo, al que Fatma daba la espalda, aparecía sobre una pared del fondo (18).

Si la ventana, como símbolo de receptividad (del mismo modo que el ojo y la conciencia) es apertura hacia el mundo exterior, la de Fatma - protegida con una gran celosía - es, a la vez, acceso a la luz y una castración; apertura que le da a la nada del protagonista y a su mundo de ausencias cierta forma, pero que la aísla al mismo tiempo del mundo exterior (la celosía):

...para Fatma, la ventana no era la caja de sus nadas, como suponían al verla, sino la puerta que la conducía a todas las cosas y a ninguna. Era el estuche de donde tomaba la sed de todo, ya que todas esas ausencias volátiles que eran el aire de su melodía, tenían raíces en las partes de su carne que más fácilmente atraviesa la imaginación (42).

La idea del espacio reductor en relación con la psicología del personaje es todavía más evidente cuando el narrador nos informa que lo que Fatma esperaba a través de estas miradas desde la ventanaclaustro "era tan solo un camino sobre el mar que la ale jara de su encierro entre tantos ceños fruncidos interrogándola sobre la espera" (32). 
La espera anuncia aquí una serie de viajes iniciáticos mentales hacia el mundo del deseo. Esta iniciación es en sí una metamorfosis y, por consiguiente, el paso a otro estado; y en el caso de Fatma, "esta tempestad callada" (26), este viaje iniciático la conducirá a un despertar de sus sentidos más profundos, una especie de incursión al mundo del deseo: "un mundo nuevo había surgido en su cuerpo" (14); "su nuevo destino de mujer se perfilaba apenas aunque su recién abandonado universo de niña ya comenzaba a ser lejano" (69); "con el tiempo se fue haciendo inevitable aceptar que Fatma se había ido a un viaje sin regreso, muy adentro de ella misma, y que su alteración era una de esas heridas que ya no cicatrizan" (23).

Esta iniciación se estructura alrededor de varios símbolos muy significativos:

- La espiral, como motivo abierto que simboliza la extensión, la emanación, y que evoca de modo general la evolución de un estado a otro: "El pájaro que llevas dentro vuela en espiral", le dice su abuela Aisha (15).

- $\quad$ El número 9, que anuncia (como último de la serie) tanto el comienzo como el final de un ciclo. La primera parte del relato consta de nueve subdivisiones, la última de las cuales está estructurada alrededor de nueve pasos introducidos por dos citas extraídas respectivamente de Hesíodo e Ibn Arabi, y cuyo denominador común es el número 9 (71).

El destino de Fatma queda así determinado por esta carga simbólica basada en la noción de apertura y acceso a un nuevo mundo. Dice la abuela de Fatma: "Con la Espiral viene el número nueve: son los pasos que te separan de tu destino, es el tiempo de tu camino en la espiral, los alcázares concéntricos que deberás traspasar" (15).

El baño moro (o el hammam), pese a ser también un espacio cerrado, es símbolo del paso de un estado a otro, especie de preludio a la manifestación. Tradicionalmente el hammam es el lugar de 
reunión de las mujeres. Es un conjunto de salas en cuyo recinto la conversación se hace más ruidosa, pero sirve de solaz y esparcimiento a personas que únicamente en raras ocasiones suelen salir de sus hogares. Es el lugar donde las mujeres "pueden tejer los hilos delgados de sus complicidades" (50). Como único lugar de purificación y limpieza, el hammam abre sus humedades durante la mañana tan sólo a los cuerpos femeninos, "reservando el agua de sus tardes para lubricar las asperezas de la complicidad masculina" (50). Se trata de un espacio iniciático por excelencia, a donde acude Fatma para satisfacer una necesidad de relajamiento, seguridad y ternura, y donde, además, descubre los misteriosos secretos de su cuerpo:

Al quitarse la ropa y sentir sobre su cuerpo la luz del sol, intensificada y coloreada por los vitrales del techo, Fatma se había sentido tocada con delicadeza por alguien que tocaba de la misma manera a todas las que entraban con ella (54).

Una bruma púrpura sube por sus muslos. Al verla, siente que ese vapor teñido amenaza morderle de nuevo los labios entre las piernas (71).

Y los huecos del hammam "eran sus propios huecos" (55).

En el hammam, lugar predilecto para tal iniciación, Fatma se imaginará caminando en una ceremonia secreta hacia su propio sacrificio; una especie de fuga hacia el mundo del deseo durante la cual sus manos se le presentarán como "cabezas desdentadas que miran por los nudillos y muerden con las yemas"; su vagina como un nido "de donde surgen empapados todos los sueños de las serpientes"; y sus pezones como "pequeñas rocas que crecen y ya no caben en sí mismos" (72).

En las profundidades de este letargo o larga espera, Fatma, "como una duna sumergida bajo la más alta marea de sus sueños" (14), parecía acoger un anhelo, pero también con muchos conflictos, este nuevo mundo y esta nueva fuerza que se habían apoderado de su 
cucrpo y que tan sólo podía realizar en el mundo del sueño o de la imaginación: el sueño como símbolo de esas aventuras individuales y la no expresión de una actividad mental. El objetivo: realizarse y expresar su nuevo destino de mujer. Sus labios "parecían delineados para moldear el sonido de las más frágiles palabras", y en sus largas piernas "los apetitos más íntimos parecían manar sobre la tensión de sus músculos" (14).

El deseo de Fatma era tal que el personaje "dejaba deslizar sus dedos sobre los labios", gesto mediante el cual intentaba recoger profundidades y "provocar la erupción de sentidos nocturnos" (42):

...dejaba caer sus dedos sobre la garganta, pintaba sobre su cuello alargadas caricias, que descendían hasta hacerse ligeramente redondas al encontrar el nacimiento de sus senos: que ya le ofrecían premiar dulces demoras en la dureza de sus cimas (43).

El personaje termina experimentando esta ilusión de placer al entrar en contacto con cualquier cosa: cualquier objeto que tuviera a su alcance; voces que "se habían abierto camino en el laberinto de su cuerpo" (47); el asombroso diálogo de la gente en la calle; en fin, la imagen final de una ciudad desnuda (Mogador) que se le presentará como "una amante esperando en sus puertas. Color de luna, la piel humedecida de sus anhelos", y cuyas murallas serán estos labios que "significan y no modulan su canto". 